\title{
Spatio-temporal associations of air pollutant concentrations, GP respiratory consultations and respiratory inhaler prescriptions: a 5-year study of primary care in the borough of Lambeth, South London
}

Mark Ashworth ${ }^{1 *}$ DD, Antonis Analitis ${ }^{2}$, David Whitney ${ }^{1}$, Evangelia Samoli², Sofia Zafeiratou ${ }^{2}$, Richard Atkinson ${ }^{3}$, Konstantina Dimakopoulou ${ }^{2}$, Sean Beavers ${ }^{1,4}$, Joel Schwartz ${ }^{5}$, Klea Katsouyanni ${ }^{2,4}$ on behalf of the STEAM project research group

\begin{abstract}
Background: Although the associations of outdoor air pollution exposure with mortality and hospital admissions are well established, few previous studies have reported on primary care clinical and prescribing data. We assessed the associations of short and long-term pollutant exposures with General Practitioner respiratory consultations and inhaler prescriptions.

Methods: Daily primary care data, for 2009-2013, were obtained from Lambeth DataNet (LDN), an anonymised dataset containing coded data from all patients (1.2 million) registered at general practices in Lambeth, an innercity south London borough. Counts of respiratory consultations and inhaler prescriptions by day and Lower Super Output Area (LSOA) of residence were constructed. We developed models for predicting daily $\mathrm{PM}_{2.5}, \mathrm{PM}_{10}, \mathrm{NO}_{2}$ and $\mathrm{O}_{3}$ per LSOA. We used spatio-temporal mixed effects zero inflated negative binomial models to investigate the simultaneous short- and long-term effects of exposure to pollutants on the number of events.

\footnotetext{
* Correspondence: mark.ashworth@kcl.ac.uk

'School of Population Health and Environmental Sciences, King's College London, Guy's Campus, Addison House, London SE1 1UL, UK

Full list of author information is available at the end of the article
}

(c) The Author(s). 2021 Open Access This article is licensed under a Creative Commons Attribution 4.0 International License, which permits use, sharing, adaptation, distribution and reproduction in any medium or format, as long as you give appropriate credit to the original author(s) and the source, provide a link to the Creative Commons licence, and indicate if changes were made. The images or other third party material in this article are included in the article's Creative Commons licence, unless indicated otherwise in a credit line to the material. If material is not included in the article's Creative Commons licence and your intended use is not permitted by statutory regulation or exceeds the permitted use, you will need to obtain permission directly from the copyright holder. To view a copy of this licence, visit http://creativecommons.org/licenses/by/4.0/. The Creative Commons Public Domain Dedication waiver (http://creativecommons.org/publicdomain/zero/1.0/) applies to the data made available in this article, unless otherwise stated in a credit line to the data. 


\begin{abstract}
(Continued from previous page)
Results: The mean concentrations of $\mathrm{NO}_{2}, \mathrm{PM}_{10}, \mathrm{PM}_{2.5}$ and $\mathrm{O}_{3}$ over the study period were 50.7, 21.2, 15.6, and $49.9 \mathrm{\mu g} / \mathrm{m}^{3}$ respectively, with all pollutants except $\mathrm{NO}_{2}$ having much larger temporal rather than spatial variability. Following short-term exposure increases to $\mathrm{PM}_{10}, \mathrm{NO}_{2}$ and $\mathrm{PM}_{2.5}$ the number of consultations and inhaler prescriptions were found to increase, especially for $\mathrm{PM}_{10}$ exposure in children which was associated with increases in daily respiratory consultations of $3.4 \%$ and inhaler prescriptions of $0.8 \%$, per $\mathrm{PM}_{10}$ interquartile range (IQR) increase. Associations further increased after adjustment for weekly average exposures, rising to 6.1 and 1.2\%, respectively, for weekly average $\mathrm{PM}_{10}$ exposure. In contrast, a short-term increase in $\mathrm{O}_{3}$ exposure was associated with decreased number of respiratory consultations. No association was found between long-term exposures to $\mathrm{PM}_{10}, \mathrm{PM}_{2.5}$ and $\mathrm{NO}_{2}$ and number of respiratory consultations. Long-term exposure to $\mathrm{NO}_{2}$ was associated with an increase (8\%) in preventer inhaler prescriptions only.

Conclusions: We found increases in the daily number of GP respiratory consultations and inhaler prescriptions following short-term increases in exposure to $\mathrm{NO}_{2}, \mathrm{PM}_{10}$ and $\mathrm{PM}_{2.5}$. These associations are more pronounced in children and persist for at least a week. The association with long term exposure to $\mathrm{NO}_{2}$ and preventer inhaler prescriptions indicates likely increased chronic respiratory morbidity.
\end{abstract}

Keywords: Air pollutants, Primary care, Respiratory illness, Inhaler prescription, Asthma, COPD

\section{Background}

The effects of short and long-term exposures to particulate and gaseous air pollution on health have been known for some time [1,2]. Most studies deal with serious health effects such as increased mortality or hospital admissions associated with both short and long-term exposures [3]. However, a larger proportion of the exposed population are likely to experience less severe effects such as respiratory conditions presenting to primary care.

Few studies have explored adverse health effects of air pollution from a primary care perspective. In a study of particulate pollution $\left(\mathrm{PM}_{10}\right)$ and monthly salbutamol inhaler prescribing in a population of 450,000 patients registered at general practices in north east England, [4], an increase of $10 \mu \mathrm{g} / \mathrm{m}^{3}$ in ambient $\mathrm{PM}_{10}$ was found to be associated with a $1 \%$ increase in salbutamol prescribing over a 55-month period. Using health insurance data, a study in France covering a population of 260,000 residents of Strasbourg found that $10 \mu \mathrm{g} / \mathrm{m}^{3}$ increases in $\mathrm{PM}_{10}$, nitrogen dioxide $\left(\mathrm{NO}_{2}\right)$, and ozone $\left(\mathrm{O}_{3}\right)$ were associated with $7.5,8.4$ and $1 \%$ increases in salbutamol sales, respectively, over a 1 year period [5]. In a population of just under one million in Brussels, a study of daily sales of asthma and COPD medication and $\mathrm{PM}_{10}$ and $\mathrm{NO}_{2}$ residential exposure found no overall association between $\mathrm{PM}_{10}$ exposure and medication sales but for $\mathrm{NO}_{2}$ exposure, significant associations were found for all age groups except the $85 \mathrm{yr}$ olds; the strongest associations were found in adolescents for whom, a one interquartile range increase in $\mathrm{NO}_{2}$ exposure was associated with an $18.7 \%$ increase in medication sales, with a 3 week lag, over a 6-year period [6]. None of these studies included clinical data. Based on a study of primary care clinical data over 2 years obtained from the General Practice Research Database between 1992 and 1994, 10th-90th percentile change in $\mathrm{PM}_{10}$ particles was associated with a $5.7 \%$ increase in upper respiratory tract conditions in adults aged 15-64 years, a 10.2\% increase in those aged 65 and over but a non-significant $2.0 \%$ increase in those aged 10-14 [7]. Stronger associations were found in the elderly and in the winter months. However, this study did not explore prescribing of inhalers for respiratory conditions.

In order to study associations between air pollution levels and primary care clinical and prescribing data, clinical database linkage is required, linking anonymised clinical and prescribing data with residential air pollution levels. Additionally, appropriate and validated air pollution models are needed to provide estimates of pollution levels at small area level. UK primary care data offers a unique resource to study these associations.

Within the context of the UK MRC funded Project STEAM (Comparative evaluation of Spatio-Temporal Exposure Assessment Methods for estimating the health effects of air pollution), spatiotemporal modelling of several pollutants providing daily data estimating concentrations of pollutants per Lower Super Output Area (LSOA) has been developed [8-10]. We therefore aimed to assess the association between short and longterm pollutant exposures and numbers of primary care respiratory consultations and inhaler prescribing, taking advantage of the U.K. universal registration system in a geographically circumscribed population.

\section{Methods}

\section{Study area and primary care data}

Primary care data were obtained from Lambeth DataNet (LDN), an anonymised dataset containing coded data from all patients registered at general practices in Lambeth, an inner-city south London borough of 26.8 
$\mathrm{km}^{2}$ [11]. Clinical and prescribing data are available on all current and past registered patients dating back to 2005, a total of 1.2 million patients. Patients are excluded from the dataset if they have an informed dissent' code in their case-notes, currently accounting for $3.2 \%$ of the registered population. Demographic information collected includes data on age, gender and ethnicity. Clinical data includes records of chronic diseases and all medication prescribed. Residential data is also available, down to Lower Super Output Area (LSOA) level, small areas which average 1500 residents in England [12]. At the time of the study, Lambeth consisted of 177 LSOAs.

For the present analysis we used aggregated daily counts, for weekdays only, since primary care data are only available for weekdays, by age group $(0-17 ; 18-64$; $65+$ years) for the total number of respiratory consultations per LSOA of residence with face to face, telephone, online, administrative consultations and home visits with GP or nurse. The total number of respiratory consultations was stratified into three groups focusing on specific respiratory outcomes for each day over the 5-year period 2009-2013: number of consultations for all asthma episodes, all Chronic Obstructive Pulmonary Disease (COPD) exacerbations and upper respiratory tract infections (URTI) ('asthma/COPD/URTI consultations'); number of prescriptions for preventer and reliever inhalers ('inhaler consultations'); total number of respiratory consultations coded for one of the included respiratory conditions \&/or issue of a preventer or reliever inhaler ('all respiratory consultations'). Inhaler prescriptions, both prescribed during a face-to-face consultation or as a repeat prescription were included, since patients often self-manage their respiratory condition through use of the repeat prescription system.

Preventer inhaler prescriptions were defined as those containing long acting beta-agonists (LABA), long acting muscarinic antagonists (LAMA) or inhaled corticosteroids (ICS). Reliever inhaler prescriptions were defined as those containing short acting beta-agonists (SABA) or short acting muscarinic antagonists (SAMA). Read and EMIS medication codes used in the analysis are available on request.

\section{Air pollution data}

Within the STEAM project, we constructed a database of ambient particles with aerodynamic diameter $<10 \mu \mathrm{m}$ and $<2.5 \mu \mathrm{m}$ (24-h average $\mathrm{PM}_{10}$ and $\mathrm{PM}_{2.5}$ ), Nitrogen Dioxide $\left(\mathrm{NO}_{2}, 24\right.$-h average $)$ and Ozone $\left(\mathrm{O}_{3}, 8\right.$-h daily maximum) concentrations including all measurements from sites within the M25 orbital motorway during the years 2009-13. Data were obtained from the London Air Quality Network [13], Air Quality England [14] and the Automatic Urban and Rural Network [15]. $\mathrm{PM}_{2.5}$ was measured in a smaller number of sites and in order to obtain more data we enhanced the available data based on a generalised additive model (GAM) combination of daily PM2.5 predictions from a regression and a random forest approach based on PM10 and $\mathrm{NO}_{2}$ measurements and incorporating seasonality trends, meteorological variables and spatial characteristics. The 10 -fold crossvalidation adjusted $\mathrm{R}^{2}$ of the combined model was 98.9\%. The final data included information from 130 sites for $\mathrm{NO}_{2}, 115$ for $\mathrm{PM}_{10}, 62$ for $\mathrm{O}_{3}$ and 104 for $\mathrm{PM}_{2.5}$ [16].

Using these data in STEAM, we developed spatiotemporal Land Use Regression (LUR), dispersion models and combinations of these to estimate pollutant concentrations at the postcode centroid level. All postcode centroids within an LSOA were then averaged to produce estimates of LSOA level concentrations. Additionally, for $\mathrm{PM}_{2.5}$, we incorporated satellite measurements and applied three machine learning algorithms that were combined in a GAM to produce spatio-temporal concentrations within 1 $\mathrm{km} \times 1 \mathrm{~km}$ grids. These models are described in more detail elsewhere [8-10]. Based on simulation studies [8, 9], a GAM model combining predicted pollutant concentrations from the developed spatio-temporal LUR and dispersion models was found to produce the smallest bias on the effect estimates. Daily time series predictions for $\mathrm{NO}_{2}, \mathrm{O}_{3}$, $\mathrm{PM}_{2.5}$ and $\mathrm{PM}_{10}$ at LSOA level for Lambeth from this minimum-bias model were used here for the present analysis of the health data.

\section{Statistical analysis}

We used, alternatively, the following outcome variables based on daily counts per LSOA over the study period 2009-13 stratified by age group $(0-17 ; 18-64 ; 65+$ years): (1) 'asthma/COPD/URTI consultations', (2) 'inhaler prescriptions', (3) 'all respiratory consultations'.

We investigated the simultaneous short- and long-term effects of exposure to $\mathrm{NO}_{2}, \mathrm{O}_{3}, \mathrm{PM}_{2.5}$ and $\mathrm{PM}_{10}$ on the outcomes $[17,18]$. To assess long-term exposure associations with the outcome, we used the mean pollution concentration of each LSOA for the whole study period, 2009-13 (spatial component of the variability), whilst for short-term effects we used the difference between daily concentrations and the long-term mean for each pollutant per LSOA (temporal component of the variability). We applied a mixed effects, zero inflated negative binomial model, including a random intercept per LSOA, using the NBZIMM library in R [19]. As covariates we used: a) covariates with daily variation (short-term): day of week (6 dummy variables), temperature (as a natural spline with 3 degrees of freedom (3df)) time trend, i.e. a variable numbering sequentially all days in the 2009-2013 period, (natural spline, 6df per year), relative humidity (natural spline, 3df) and b) covariates characterizing each LSOA 
(long-term): proportion of elderly residents (\% aged $\geq 65$ years), Index of Multiple Deprivation 2015 [20]. The number of observations was 1304 days per LSOA. We also considered confounding between pollutants and adjusted for pollutants likely to cause confounding effects, for example, for ozone and $\mathrm{PM}$ we adjusted for $\mathrm{NO}_{2}$ whilst for $\mathrm{NO}_{2}$ effect estimates we adjusted for $\mathrm{PM}_{2.5}$.

As a sensitivity analysis, we fitted Poisson models to investigate the short-term associations between daily concentrations of pollutants over the entire sample area and the selected clinical and prescribing data in order to compare their performance with our spatio-temporal models.

\section{Results}

Daily consultation and prescribing data for the study area are summarised in Table 1 . Over the study period, the mean number of all respiratory consultations per LSOA, per day was 522.23. Stratification of consultations according to diagnostic code shows that many were not assigned an 'asthma/COPD/URTI consultation' code but nevertheless resulted in a prescription for a preventer \&/or reliever inhaler.

The level and variability of air pollution and meteorological values for temperature and humidity are summarised in Table 2 displaying daily, 'temporal' variability and 'spatial variability'. In Table 2, for air pollutants, concentrations are shown, not deviations from a longterm mean as used in the models, to illustrate the data in a clearer way. $\mathrm{PM}_{10}, \mathrm{PM}_{2.5}$ and $\mathrm{O}_{3}$ have much higher temporal than spatial variability and only $\mathrm{NO}_{2}$, which is largely related to traffic sources, has approximately equal temporal and spatial variability. Temporal and spatial correlation coefficients between air pollutants are summarized in Table 3.

Table 4 shows the \% change in the number of all respiratory consultations' and 'asthma/COPD/URTI consultations' following short-term (lag 0) and longterm increase in exposure to each pollutant equal to an interquartile range (IQR) increase. Following increases of short-term exposure to $\mathrm{PM}_{10}, \mathrm{NO}_{2}$ and $\mathrm{PM}_{2.5}$ the number of all daily respiratory and asthma/COPD/URTI consultations' increase for all age groups and reach statistical significance with few exceptions; the largest increase in consultations is generally observed for children: 3.04\% (95\% confidence intervals, 2.41, 3.67) ('all respiratory consultations') and $3.38 \%(95 \% \mathrm{CIs} 2.65,4.11)$ ('asthma/COPD/URTI consultations') for $\mathrm{PM}_{10}$ per IQR; also $2.37 \%$ (95\%CIs $1.47,3.28)$ and $1.37 \%$ (95\%CIs 0.34 , 2.40) respectively per IQR for $\mathrm{NO}_{2}$. However, a shortterm increase in $\mathrm{O}_{3}$ exposure is associated with a significant decrease in the number of consultations. In contrast, there is no association between long-term exposures to $\mathrm{PM}_{10}, \mathrm{PM}_{2.5}$ and $\mathrm{NO}_{2}$ and consultation rates in adults; in children increased long-term exposure to $\mathrm{NO}_{2}$ and $\mathrm{PM}_{2.5}$ is associated with lower consultation rates. Long-term increase in $\mathrm{O}_{3}$ exposure is not associated with a change in the number of consultations, with the exception of a $20 \%$ increase in the number of all respiratory consultations for the $65+$ years age group.

Table 5 shows the \% change in the number of inhaler prescriptions overall and for preventive and reliever inhalers separately following short-term or long term exposure to each pollutant. The number of prescriptions for both types of inhalers increase by $2.14 \%$ (95\%CIs 1.54, 2.75) after short-term increase in $\mathrm{NO}_{2}$ exposure and by $0.84 \%(95 \% \mathrm{CIs} 0.42,1.26)$ after short-term increase in $\mathrm{PM}_{10}$ exposure. There is no significant association with short-term exposure changes to $\mathrm{PM}_{2.5}$ and $\mathrm{O}_{3}$. An increase in long-term exposure to $\mathrm{NO}_{2}$ is associated with an increase of $8.11 \%(95 \% \mathrm{CIs} 1.03,15.69)$ in preventer inhaler prescriptions only, whilst an increase is also observed for prescriptions of preventer inhalers following long-term increases in exposure to $\mathrm{PM}_{10}$ and $\mathrm{PM}_{2.5}$ as well, although not reaching the nominal level of statistical significance. A change in long-term exposure to $\mathrm{O}_{3}$ is not associated with significant changes in the number of prescriptions.

Figures 1 and 2 show the \% changes in the number of consultations and prescriptions associated with an IQR increase in pollutant exposure for lags $0,1,2$ and the mean of 7 days (weekly), namely lags $0-6$. For $\mathrm{NO}_{2}$ exposure increase, the daily number of all respiratory consultations increases with 1- and 2-day lags and the

Table 1 Daily respiratory consultation and prescribing data for Lambeth (all LSOAs combined) by age group 2009-13 (aggregated time series for total of 1304 days)

\begin{tabular}{lllll}
\hline & $\begin{array}{l}\text { Age 0-17 years } \\
\text { Mean (SD) }\end{array}$ & $\begin{array}{l}\text { Age 18-64 years } \\
\text { Mean (SD) }\end{array}$ & $\begin{array}{l}\text { Age > 64 years } \\
\text { Mean (SD) }\end{array}$ & $\begin{array}{l}\text { All ages } \\
\text { Mean (SD) }\end{array}$ \\
\hline Total respiratory consultations ${ }^{\text {a }}$ & $123.33(48.79)$ & $290.47(74.05)$ & $108.43(28.04)$ & $522.23(137.58)$ \\
Consultations for asthma, COPD, URTI & $84.09(40.20)$ & $133.23(47.14)$ & $34.75(12.14)$ & $252.07(90.49)$ \\
Prescriptions for preventer inhaler only & $5.35(2.91)$ & $33.38(9.86)$ & $22.28(7.31)$ & $61.01(16.19)$ \\
Prescriptions for reliever inhaler only & $26.74(10.15)$ & $74.43(20.69)$ & $27.27(8.55)$ & $128.43(34.32)$ \\
Prescriptions for both inhaler types & $15.95(6.34)$ & $71.16(18.30)$ & $30.45(9.70)$ & $117.55(29.90)$ \\
\hline
\end{tabular}

${ }^{a}$ Consultations by any primary care healthcare professional including those where only a preventer or reliever inhaler were issued 
Table 2 Means, standard deviations (SD) and quartiles of daily pollutant concentrations and meteorological variables for the whole area of Lambeth, 2009-13 (temporal variability) and for daily pollutant concentrations, per LSOA in Lambeth (177 LSOAs), for 200913 (spatial variability)

\begin{tabular}{|c|c|c|c|c|c|c|c|c|c|c|}
\hline & \multicolumn{5}{|c|}{ Temporal variability } & \multicolumn{5}{|c|}{ Spatial variability } \\
\hline & $\begin{array}{l}\text { Mean } \\
\text { (SD) }\end{array}$ & $\begin{array}{l}\text { 1st } \\
\text { Quartile }\end{array}$ & $\begin{array}{l}\text { 2nd } \\
\text { Quartile }\end{array}$ & $\begin{array}{l}\text { 3rd } \\
\text { Quartile }\end{array}$ & $\mathrm{IQR}^{\mathrm{a}}$ & $\begin{array}{l}\text { Mean } \\
\text { (SD) }\end{array}$ & $\begin{array}{l}\text { 1st } \\
\text { Quartile }\end{array}$ & $\begin{array}{l}\text { 2nd } \\
\text { Quartile }\end{array}$ & $\begin{array}{l}\text { 3rd } \\
\text { Quartile }\end{array}$ & $I Q R^{a}$ \\
\hline $24 \mathrm{~h} \mathrm{NO}_{2}\left(\mu \mathrm{g} / \mathrm{m}^{3}\right)$ & $50.7(15.4)$ & 39.1 & 49.7 & 61.4 & 22.3 & $48.4(16.3)$ & 36.6 & 45.1 & 57.6 & 21.0 \\
\hline $24 \mathrm{~h} \mathrm{PM}_{10}\left(\mu \mathrm{g} / \mathrm{m}^{3}\right)$ & $21.2(8.8)$ & 15.2 & 18.6 & 24.3 & 9.1 & $20.8(2.6)$ & 19.2 & 20.3 & 21.1 & 1.9 \\
\hline $24 \mathrm{~h} \mathrm{PM} 2.5\left(\mu \mathrm{g} / \mathrm{m}^{3}\right)$ & $15.6(8.2)$ & 10.3 & 12.8 & 17.9 & 7.6 & $15.4(1.2)$ & 14.5 & 15.0 & 16.0 & 1.5 \\
\hline $8 \mathrm{~h} \mathrm{O}_{3}\left(\mu \mathrm{g} / \mathrm{m}^{3}\right)$ & $49.9(18.5)$ & 37.6 & 50.2 & 61.9 & 24.3 & $50.7(4.7)$ & 48.8 & 52.0 & 54.3 & 5.5 \\
\hline $\begin{array}{l}24 \mathrm{~h} \text { temperature } \\
\left({ }^{\circ} \mathrm{C}\right)\end{array}$ & $11.0(5.7)$ & 7.0 & 11.3 & 15.3 & & & & & & \\
\hline $\begin{array}{l}24 \mathrm{~h} \text { relative } \\
\text { humidity }(\%)\end{array}$ & $77.2(10.1)$ & 70.1 & 77.8 & 85.1 & & & & & & \\
\hline
\end{tabular}

aQR interquartile range

association is greatest with the weekly average lag. The lag effect is particularly pronounced for $0-17$ year olds where an IQR increase in $\mathrm{NO}_{2}$ concentrations over the previous week is associated with 6.5\% increase in all respiratory consultations. For $\mathrm{PM}_{10}$ exposure IQR increases in 0-, 1- and 2-day lags are associated with increases in all respiratory consultations; the largest increase is associated with weekly average lag especially in 0-17 year olds (6.1\%; 95\%CI: 5.0 to $7.3 \%)$. Similar patterns are seen with $\mathrm{PM}_{2.5}$ exposure with the strongest association for weekly average lag values especially in 0 17 year olds (3.1\%; 95\%CI: 2.1 to $4.1 \%$ ). In contrast, IQR increases in $\mathrm{O}_{3}$ exposure for all lags are consistently associated with decreases in the number of all respiratory consultations.

Figures 3 and 4 shows results for short-term exposure from two pollutant models thus adjusting for possible confounding effects between pollutants. The effect estimates adjusting for another pollutant convey the same general pattern of effects even though in some instances the estimates lose statistical significance. This happens for some time lags for $\mathrm{PM}_{2.5}$ and $\mathrm{PM}_{10}$ adjusting for $\mathrm{NO}_{2}$. The ozone effects remain inverse and statistically significant. The ozone model was also adjusted alternatively for $\mathrm{PM}_{2.5}$ and the effect patterns were not

Table 3 Temporal (daily average over all LSOAS) and spatial (overall 2009-13 mean per LSOA) correlation coefficients for the pollutants

\begin{tabular}{|c|c|c|c|c|c|c|c|c|}
\hline & \multicolumn{4}{|c|}{ Temporal correlations } & \multicolumn{4}{|c|}{ Spatial correlations } \\
\hline & $\mathrm{O}_{3}$ & $\mathrm{NO}_{2}$ & $\mathrm{PM}_{10}$ & $\mathrm{PM}_{2.5}$ & $\overline{\mathrm{O}_{3}}$ & $\mathrm{NO}_{2}$ & $\mathrm{PM}_{10}$ & $\mathrm{PM}_{2.5}$ \\
\hline $\mathrm{O}_{3}$ & 1 & & & & 1 & & & \\
\hline $\mathrm{NO}_{2}$ & -0.60 & 1 & & & -0.55 & 1 & & \\
\hline $\mathrm{PM}_{10}$ & -0.19 & 0.55 & 1 & & -0.83 & 0.70 & 1 & \\
\hline $\mathrm{PM}_{2.5}$ & -0.29 & 0.61 & 0.96 & 1 & -0.80 & 0.58 & 0.75 & 1 \\
\hline
\end{tabular}

changed. Effect estimates for long-term exposures do not change appreciably.

As a sensitivity analysis, we fitted Poisson time series models, as they are commonly applied in the investigation of health effects of short-term exposures [21], to assess the stability of the estimated effects of short-term exposures to pollutants. In this application, the daily pollutant concentrations were averaged over the Lambeth area. Although the pattern of the observed associations is similar, the level of statistical significance is less pronounced indicating that the use of spatially resolved data in the spatio-temporal models shown above adds some information to the analysis (data not shown).

\section{Discussion}

In our spatio-temporal analysis of primary care data over a 5-year period (2009-13) we found that same day as well as previous 1 or 2 day or weekly average increases in $\mathrm{NO}_{2}$ and $\mathrm{PM}_{10}$ exposure are associated with significant increases in respiratory consultations, inhaler prescriptions, or both. The association was strongest for one-week average $\mathrm{NO}_{2}$ and $\mathrm{PM}_{10}$ exposure. A one quartile, oneweek average increase in $\mathrm{NO}_{2}$ or $\mathrm{PM}_{10}$ was associated with approximate 3 and $4 \%$ increases respectively, in asthma/COPD/URTI consultations, and with 4 and $1.5 \%$ increases in inhaler prescriptions. When stratified by age, the strongest association was in the younger age group (0-17 years) in which one quartile, one-week average increases in $\mathrm{NO}_{2}$ and $\mathrm{PM}_{10}$ were associated with approximate 7 and 6\% increases in consultations for asthma, COPD or URTI. The positive association with inhaler prescriptions was not substantially different between preventer and reliever inhalers.

Associations between $\mathrm{PM}_{2.5}$ exposure and respiratory consultations followed a similar pattern to those of $\mathrm{PM}_{10}$ exposure but were weaker. A one quartile, one-week average increase in $\mathrm{PM}_{2.5}$ was associated with an approximate 
Table 4 Change in the number of respiratory consultations (\% and 95 Confidence Intervals (CI)) associated with an interquartile increase in short- (daily, 'lag $\mathrm{O}^{\prime}$ ) and long- (2009-2013) term $\mathrm{NO}_{2}, \mathrm{PM}_{10}, \mathrm{PM}_{2.5}$ and $\mathrm{O}_{3}$ concentrations. Results from mixed effects zero-inflated negative binomial model adjusting for day of the week, temperature, relative humidity, time trend, proportion of elderly residents and index of multiple deprivation

\begin{tabular}{|c|c|c|c|c|c|}
\hline Air pollutant & $\begin{array}{l}\text { Outcome variable: change } \\
\text { in consultations }\end{array}$ & All ages & $0-17$ years & $18-64$ years & $65+$ years \\
\hline \multirow[t]{6}{*}{$\mathrm{NO}_{2}$} & Short term, \% change $(95 \% \mathrm{Cl})$ & & & & \\
\hline & Total respiratory consultations & $1.16(0.69,1.63)$ & $2.37(1.47,3.28)$ & $1.16(0.56,1.77)$ & $2.16(1.20,3.13)$ \\
\hline & Consultations for asthma, COPD, URTI & $0.92(0.25,1.59)$ & $1.37(0.34,2.40)$ & $0.52(-0.34,1.39)$ & $1.90(0.44,3.38)$ \\
\hline & Long term, \% change $(95 \% \mathrm{Cl})$ & & & & \\
\hline & Total respiratory consultations & $2.15(-3.76,8.43)$ & $-7.89(-14.62,-0.63)$ & $4.85(-1.43,11.52)$ & $7.11(-1.83,16.88)$ \\
\hline & Consultations for asthma, COPD, URTI & $0.83(-7.57,9.99)$ & $-8.51(-15.96,-0.40)$ & $5.59(-3.34,15.35)$ & $5.21(-9.79,22.71)$ \\
\hline \multirow[t]{6}{*}{$\mathrm{PM}_{10}$} & Short-term \% change $(95 \% \mathrm{Cl})$ & & & & \\
\hline & Total respiratory consultations & $1.01(0.68,1.34)$ & $3.04(2.41,3.67)$ & $0.79(0.37,1.22)$ & $1.06(0.40,1.72)$ \\
\hline & Consultations for asthma, COPD, URTI & $1.98(1.50,2.46)$ & $3.38(2.65,4.11)$ & $1.36(0.75,1.98)$ & $1.40(0.39,2.41)$ \\
\hline & Long-term \% change $(95 \% \mathrm{Cl})$ & & & & \\
\hline & Total respiratory consultations & $0.18(-2.95,3.42)$ & $-1.18(-5.15,2.95)$ & $0.79(-2.48,4.17)$ & $0.92(-3.72,5.79)$ \\
\hline & Consultations for asthma, COPD, URTI & $0.24(-4.31,5.00)$ & $-0.91(-5.35,3.73)$ & $1.67(-3.02,6.58)$ & $-1.26(-9.07,7.23)$ \\
\hline \multirow[t]{6}{*}{$\mathrm{PM}_{2.5}$} & Short-term \% change $(95 \% \mathrm{Cl})$ & & & & \\
\hline & Total respiratory consultations & $0.19(-0.12,0.51)$ & $1.40(0.81,2.00)$ & $0.02(-0.39,0.43)$ & $0.35(-0.28,0.97)$ \\
\hline & Consultations for asthma, COPD, URTI & $0.78(0.33,1.24)$ & $1.61(0.92,2.30)$ & $0.36(-0.22,0.95)$ & $0.66(-0.29,1.62)$ \\
\hline & Long-term \% change $(95 \% \mathrm{Cl})$ & & & & \\
\hline & Total respiratory consultations & $-2.41(-7.85,3.35)$ & $-8.42(-14.85,-1.49)$ & $1.21(-4.65,7.43)$ & $-2.85(-10.77,5.78)$ \\
\hline & Consultations for asthma, COPD, URTI & $-3.52(-11.27,4.91)$ & $-9.51(-16.59,-1.82)$ & $2.16(-6.20,11.25)$ & $-7.38(-20.17,7.45)$ \\
\hline \multirow[t]{6}{*}{$\mathrm{O}_{3}$} & Short-term \% change $(95 \% \mathrm{Cl})$ & & & & \\
\hline & Total respiratory consultations & $-2.62(-3.26,-1.98)$ & $-5.01(-6.18,-3.83)$ & $-2.69(-3.52,-1.85)$ & $-3.38(-4.65,-2.10)$ \\
\hline & Consultations for asthma, COPD, URTI & $-2.87(-3.78,-1.95)$ & $-4.58(-5.93,-3.20)$ & $-2.27(-3.46,-1.06)$ & $-1.95(-3.92,0.06)$ \\
\hline & Long-term \% change $(95 \% \mathrm{Cl})$ & & & & \\
\hline & Total respiratory consultations & $2.18(-2.83,7.44)$ & $5.12(-1.43,12.11)$ & $-0.09(-5.19,5.28)$ & $3.76(-3.63,11.71)$ \\
\hline & Consultations for asthma, COPD, URTI & $5.95(-16.53,9.58)$ & $5.83(-1.52,13.73)$ & $2.03(-5.32,9.95)$ & $20.21(5.88,36.49)$ \\
\hline
\end{tabular}

$2 \%$ increase in asthma/COPD/URTI consultations and a $4 \%$ increase in the younger age group. However, the issuing of inhaler prescriptions was not significantly associated with $\mathrm{PM}_{2.5}$ exposure.

The pattern of association with ozone exposure was very different to that of the other air pollutants included in our study. Interquartile increases in ozone exposure were generally associated with reductions in respiratory consultations and inhaler prescriptions. This negative association persisted across different lag periods and age groups.

For long-term exposures, we found no statistically significant consistent associations between exposure to any pollutant and respiratory consultations, except for children where an inverse association is found. This latter result may be due to chance or to a possible residual effect of the positive association with short-term exposure. An increase in long-term exposure to $\mathrm{NO}_{2}$ is associated with an increase (8\%) in preventer inhaler prescriptions, whilst an increase is also observed for prescriptions of preventer inhalers following long-term increases in exposure to $\mathrm{PM}_{10}$ and $\mathrm{PM}_{2.5}$, although not reaching the nominal level of statistical significance. This finding may also be due to chance, however it is noted that the use of preventer inhalers indicates a chronic condition whilst the use of reliever inhalers indicates an exacerbation and thus it is expected to see an association of long-term exposure not with indicators of an exacerbation but with indices of chronic conditions. One reason for not detecting statistically significant associations with long-term exposures may be the relatively small geographical area included in this analysis which limits the spatial contrast in pollution exposure. The clinical and prescription data analysed here are not commonly available for many boroughs. However, our findings indicate that they represent important outcomes for public health protection and it is important that such data should become available for larger areas for future work. 


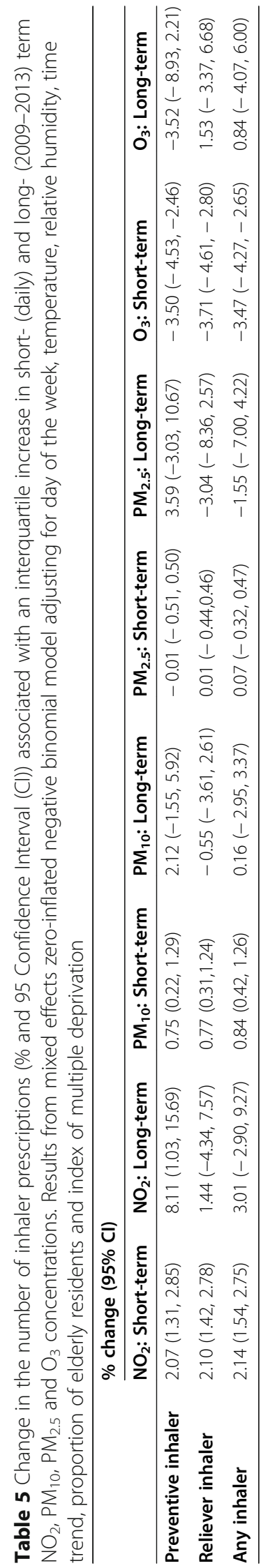



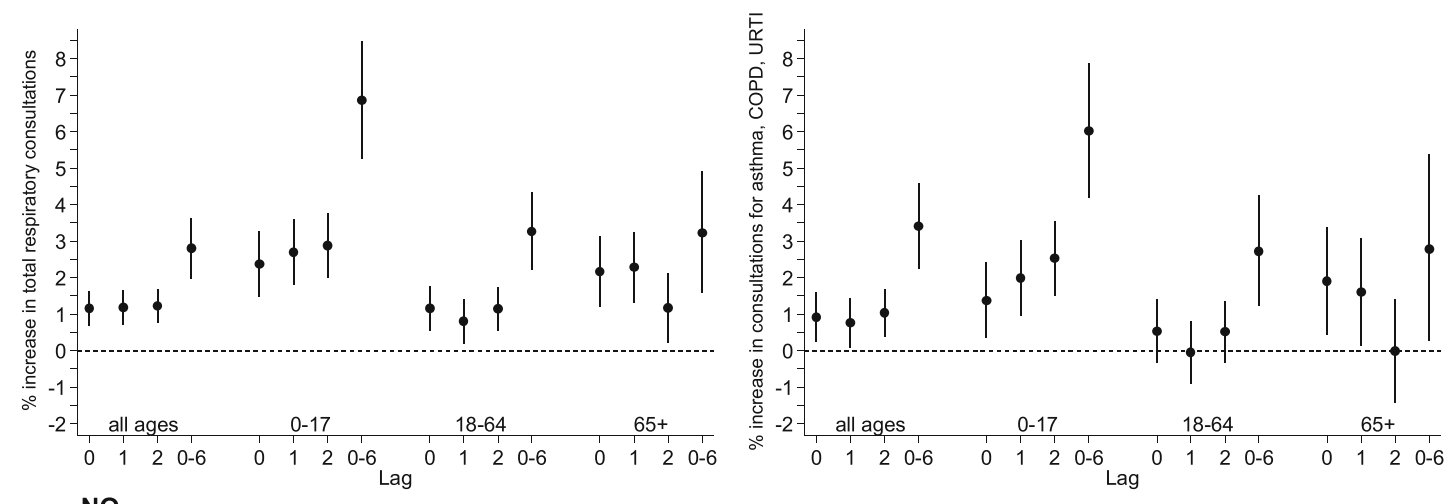

$\mathrm{NO}_{2}$
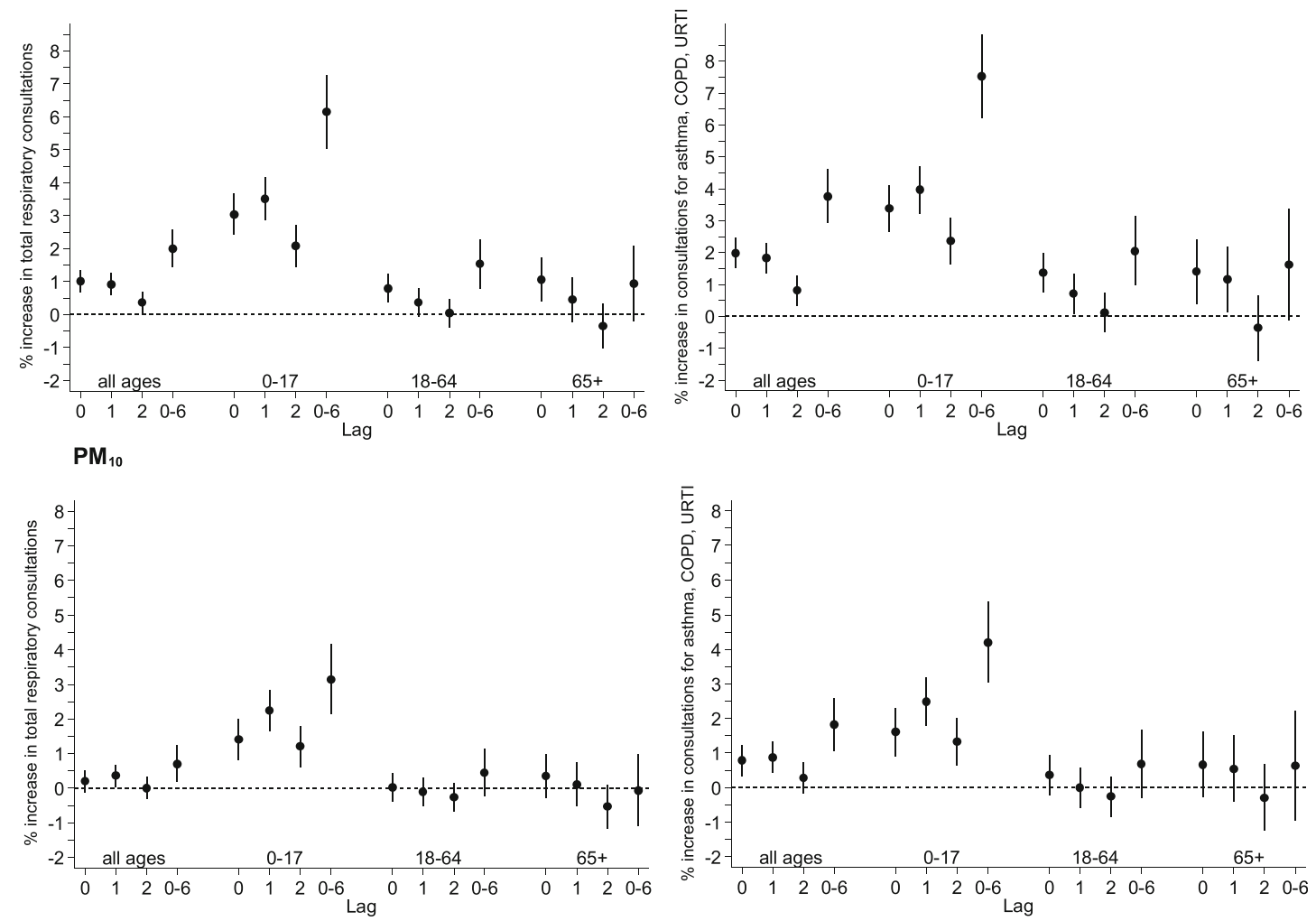

$\mathrm{PM}_{2.5}$
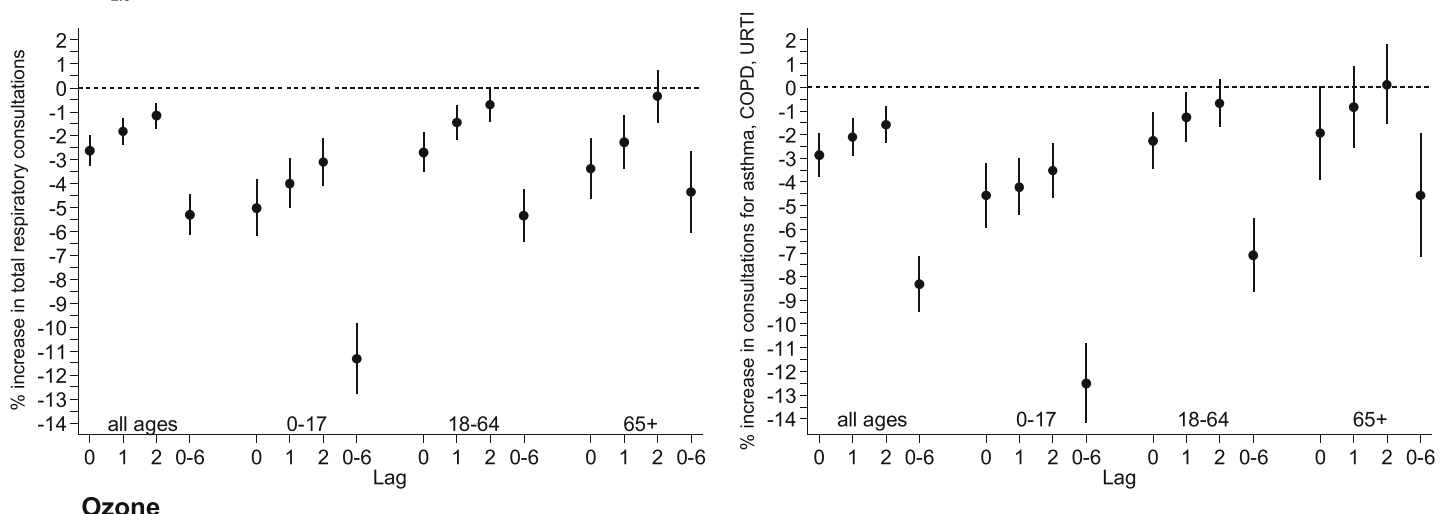

Fig. 1 (See legend on next page.) 
(See figure on previous page.)

Fig. 1 Change in the number of respiratory consultations, expressed as 'total respiratory consultations' and 'asthma/COPD/URTI consultations', (\% and 95 Confidence Interval (CI)) associated with an interquartile increase in same day (lag 0), previous day (lag 1), previous 2 days (lag2) and previous week average (lag0-6) for $\mathrm{NO}_{2}, \mathrm{PM}_{10}, \mathrm{PM}_{2.5}$ and $\mathrm{O}_{3}$ concentrations, by age group.. Results from mixed effects zero-inflated negative binomial model adjusting for day of the week, temperature, relative humidity, time trend, proportion of elderly residents and index of multiple deprivation. Note: $\mathrm{X}$ axis values represent the lags used in days. Lag 0 estimates for each air pollutant are the same as short-term values presented in Table 3

We applied spatio-temporal models assessing the effects of short- and long-term exposures concurrently and thus quantifying their independent effects. In the most usual types of analysis, the effects of short-term air pollution exposures are estimated by Poisson models, whilst the effects of long-term exposures are estimated by Cox proportional hazard models [17, 22]. Kloog et al. developed mixed Poisson regression models, as used in the present analysis [18]. This approach allows the counts of a health outcome by area to be modelled simultaneously as a function of both long- and short-term exposures. These models have been used previously in studies investigating the effects of air pollution exposure on mortality [17] and hospital admissions [23]. There is evidence on both the effects of short and long-term exposures of $\mathrm{PM}$ and $\mathrm{NO}_{2}$ on mortality: higher short-term exposures are associated with an acute increase in the number of deaths in a population whilst long-term exposures are associated with shorter life expectancy. There is also evidence that short-term elevations in air pollution concentrations result in higher number of hospital admissions, increased symptoms, absenteeism etc. [24-27]. Long term exposure to $\mathrm{PM}_{2.5}$ and $\mathrm{O}_{3}$ has been found to be associated with first hospital admissions for over 65 's with stroke, COPD, pneumonia, myocardial infarction, lung cancer and heart failure [28]. However, it is not entirely clear how long-term exposures affect hospital admission counts or other health events related to primary care. One plausible way is by enlarging the pool of sensitive individuals, for example those with chronic respiratory or cardiac diseases who then are more sensitive to short-term increases in air pollution. This would also result in a more pronounced short-term effect signal.

In our analysis we have used spatiotemporal modelling for primary health care data. Few previous studies analysed similar health outcomes. In the study of monthly data for an area in North-east England [4] a $10 \mu \mathrm{g} / \mathrm{m}^{3}$ increase in $\mathrm{PM}_{10}$ was associated with a $1 \%$ increase in salbutamol prescriptions. This is comparable to our finding for reliever inhaler prescriptions for a similar exposure change in 1-day $\mathrm{PM}_{10}$ (we used the IQR which is
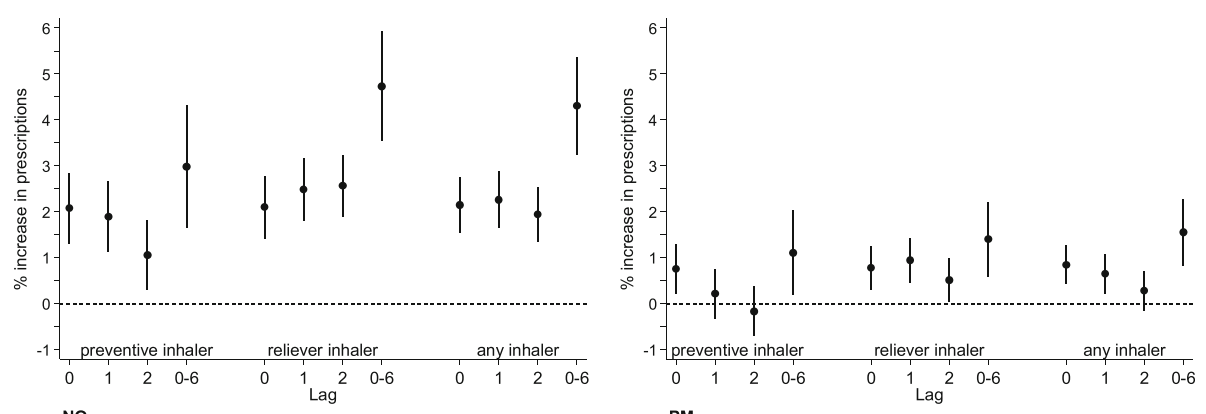
$\mathrm{NO}_{2}$

$\mathrm{PM}_{10}$
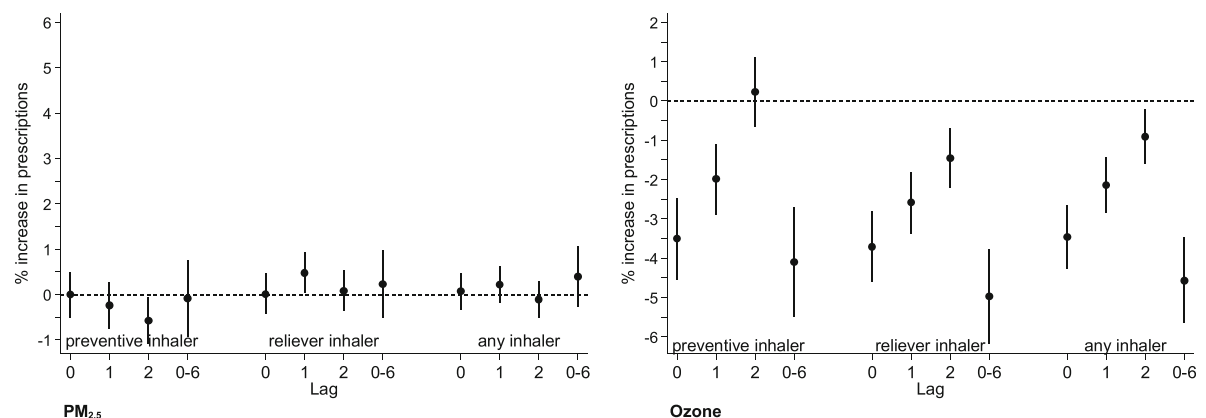

Fig. 2 Change in the number of inhaler prescriptions (\% and 95 Confidence Interval (CI)) associated with an interquartile increase in same day (lag 0), previous day (lag 1), previous 2 days (lag2) and previous week average (lag0-6) for $\mathrm{NO}_{2}, \mathrm{PM}_{10}, \mathrm{PM}_{2.5}$ and $\mathrm{O}_{3}$ concentrations. Inhaler prescription data is expressed as 'inhaler consultations'. Note: $X$ axis values represent the lags used in days. Lag 0 estimates for each air pollutant are the same as short-term values presented in Table 4 

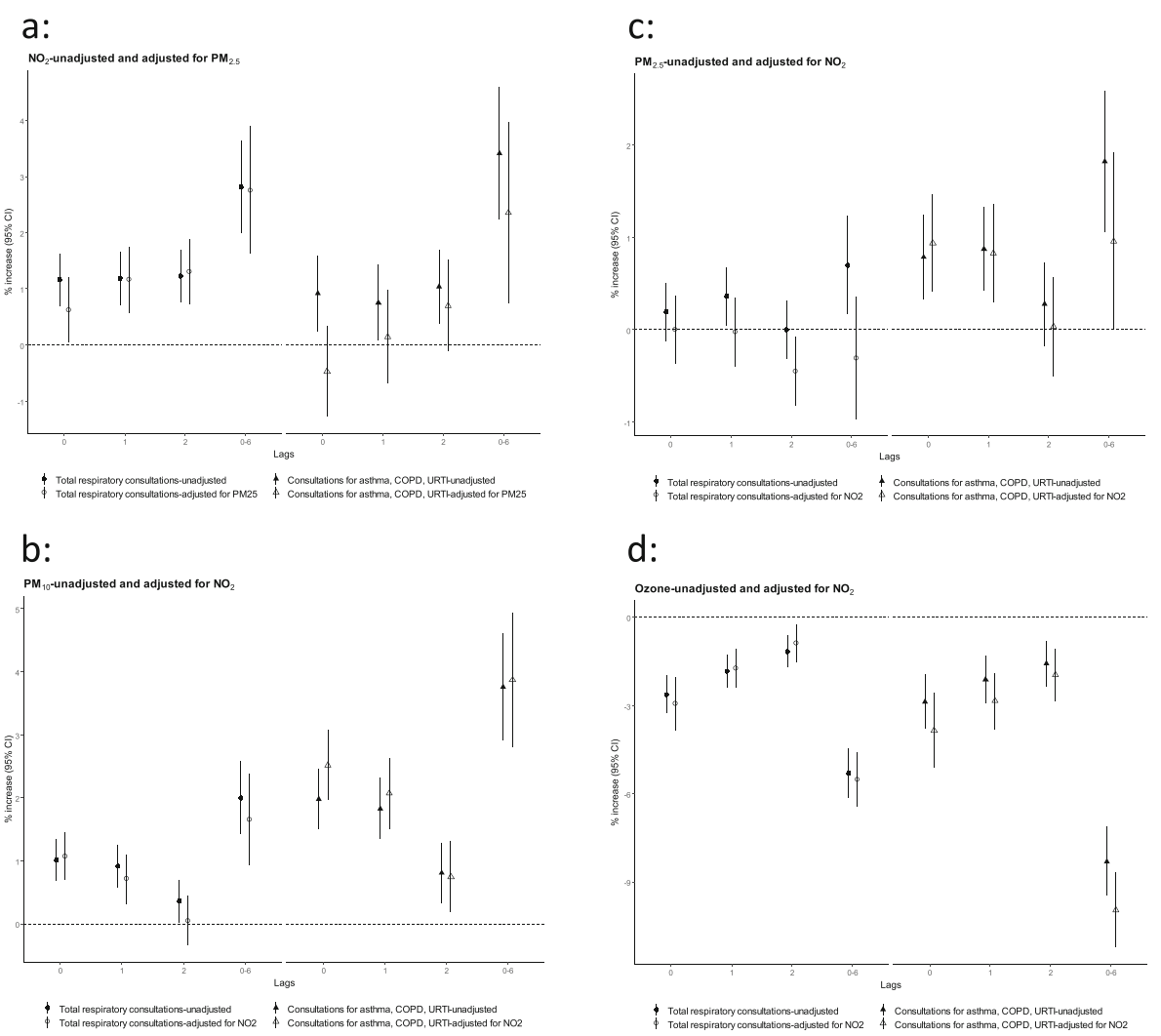

Fig. 3 a-d Change in the number of 'all respiratory consultations' (\% and 95 Confidence Interval (Cl)) associated with an interquartile increase for $\mathrm{NO}_{2}, \mathrm{PM}_{10}, \mathrm{PM}_{2.5}$ and $\mathrm{O}_{3}$ concentrations, with same day and lag phases, adjusted for confounding by other pollutants

$9.1 \mu \mathrm{g} / \mathrm{m}^{3}$ ) and for weekly changes in adults. However, we find a much larger increase for weekly changes in prescriptions for children, whilst Sofianopoulou et al did not report analysis by age groups.

Our finding of an inverse relationship between shortterm ozone elevations and the number of consultations or prescriptions was not expected and we did not find similar reports in the literature. A possible explanation may be that ozone is associated with sunny weather and high temperatures and our analysis focuses on primary care consultations; it seems plausible that good weather is associated with fewer respiratory tract infections resulting in fewer triggers to asthma or COPD exacerbation.

In our analysis, long-term exposure associations explored the spatial component of variability. In contrast to the significance of the effects of short-term exposures we do not observe significant effects of long-term exposures on GP consultations nor on overall inhaler prescriptions (with the exception of the $\mathrm{NO}_{2}$ association with preventer prescriptions). However, the number of daily observations used to assess the temporal variation is 1304 over a 5 -year period, whilst the number of spatial units available for the analysis is smaller $(n=177)$ thus providing smaller statistical power to detect effects of long-term exposure.
All primary care data were obtained from routinely recorded consultation and prescribing activity data. Only data from coded consultations were extracted within Lambeth DataNet, thus excluding access to narrative text which may have contained additional reference to respiratory symptoms. Similarly, although almost all primary care inhaler prescribing is captured through electronic prescribing, occasional hand-written prescriptions may be issued on home visits and out-of-hours inhaler prescribing may not be transcribed into coded primary care data. Almost the entire UK population is registered with a GP (universal healthcare provision) with the exception of a few extreme socially excluded people such as the homeless. Missing data is likely to result in underestimates of the strength of association with exposure. Nevertheless, primary health care outcome data concern a much larger proportion of the population than studies of secondary care outcomes and may be considered to be more important in terms of improving the health of communities. The main limitation of our study is the relatively restricted area coverage which was due to lack of available linked primary care health research data covering defined geographical areas, which leads to decreased power for detecting associations between spatial variability and long-term exposures. Lack of weekend 

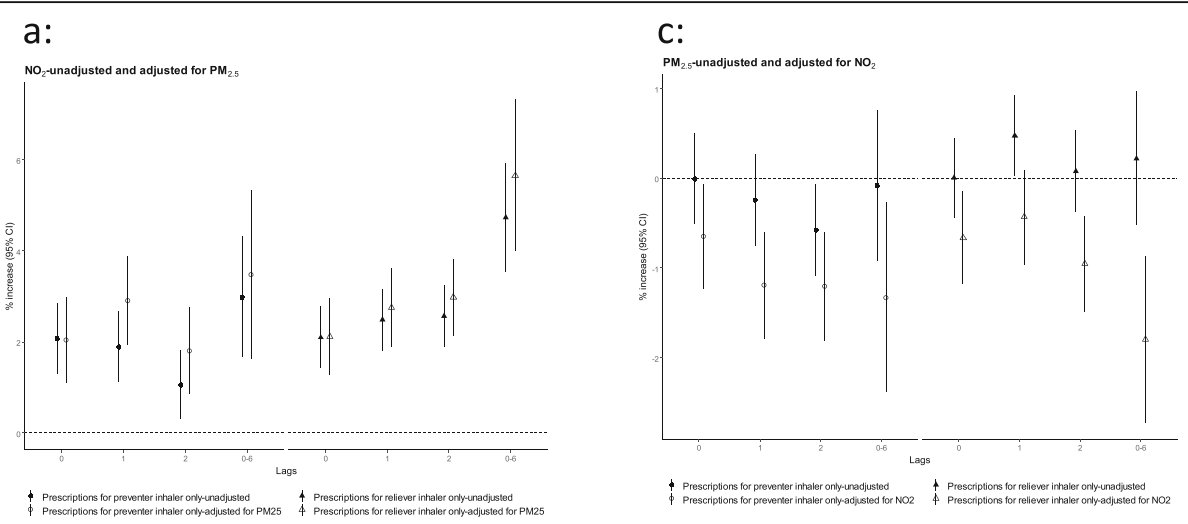

b:

$\mathrm{d}$ :
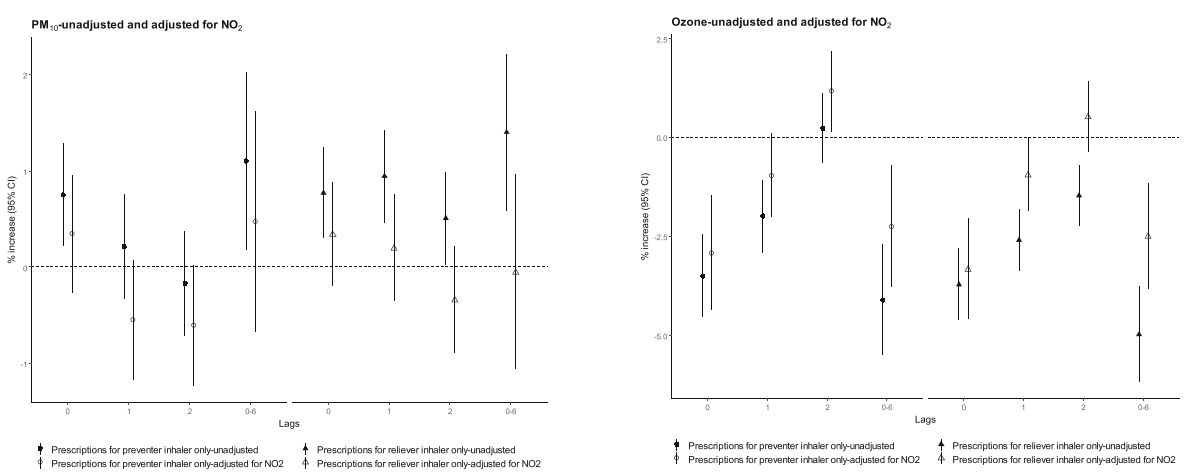

Fig. 4 a-d Change in the number of 'inhaler consultations' (\% and 95 Confidence Interval (CI)) associated with an interquartile increase for $\mathrm{NO}_{2}$ $\mathrm{PM}_{10}, \mathrm{PM}_{2.5}$ and $\mathrm{O}_{3}$ concentrations, with same day and lag phases, adjusted for confounding by other pollutants

data on respiratory consultations in primary care may have reduced the exposure variability and led to underestimation of the strength of association. Additionally, the data are anonymised, thus not allowing the identification of events belonging to the same individual.

Exposure to air pollution was estimated based on LSOA of residence although working age adults are likely to be exposed to air pollutants within several LSOAs based on travel and place of work. Our study finding of stronger associations in $0-17$ year olds between air pollution levels and respiratory consultations/ inhaler prescriptions may be the result of increased vulnerability or confounded by lower daytime travel in this age group, especially during times of school holidays. Aggregated LSOA data is likely to underestimate the effect of individual level deprivation and may have resulted in underestimates of spatial confounding.

The present investigation became possible because of the availability of spatio-temporal models developed in the STEAM project [8-10]. These models combine a dispersion and a Land Use Regression model and, for $\mathrm{PM}_{2.5}$, the addition of satellite data and machine learning methods. They predict on a daily basis and provide estimates per LSOA (based on an average of predictions for all post-code centroids included in an LSOA). It is evident that even the most dense fixed site monitoring network cannot provide an adequate spatial resolution for such a spatiotemporal health analysis. Hybrid models open the way for more powerful and sophisticated analyses leading to a better understanding of health effects.

These detailed spatio-temporal models had a stronger predictive ability at the temporal rather than the spatial scale. For example, the $\mathrm{PM}_{2.5}$ model has a spatial $\mathrm{R}^{2}$ equal to 0.40 and a temporal $R^{2}$ of 0.88 [10]. This limits the interpretation of respiratory health associations with the spatial component of $\mathrm{PM}_{2.5}$ variability in our analysis. European air pollutant values are atypical in some respects. Higher usage of light duty diesel vehicles and differences in heavy industry in European countries results in relatively low $\mathrm{PM}$ and high $\mathrm{NO}_{2}$ levels compared to non-European contexts such as Asian and North America $[29,30]$. Future work is needed to improve the prediction of the spatial variability component and to develop such models for other geographical areas, as the consequences of air pollution have to be considered in a global context.

A further limitation of our study is that we use aggregated data, albeit data aggregated at a very fine spatial level, and thus we are not able to include information on individual confounders in the models. We have included 
only LSOA level confounders, specifically age distribution and deprivation index. It is possible that this level of adjustment does not fully control for the relevant confounders.

\section{Conclusion}

In conclusion, our study is one of the few to investigate the associations of short- and long-term exposure to ambient $\mathrm{PM}, \mathrm{NO}_{2}$ and ozone air pollutants with commonly occurring primary care respiratory consultations and the prescribing of respiratory inhalers.

Short term increases in $\mathrm{PM}$ and $\mathrm{NO}_{2}$ are associated with increased asthma, COPD and URTI consultations for all ages. These associations are most pronounced in children and with sustained, one-week elevations in air pollutants. Similar for $\mathrm{NO}_{2}$ but less strong for PM, associations are also seen with both preventer and reliever inhaler prescriptions.

Higher levels of ozone exposure were associated with lower rates of respiratory consultations and inhaler prescriptions, possibly the result of known associations between high ozone levels and hot and sunny weather.

There is a need to for more studies investigating air pollutants exposure over sustained periods with primary care data covering wider geographical areas and larger populations.

\section{Acknowledgements}

Not applicable.

\section{Authors' contributions}

MA: Conceptualization, Investigation, Supervision, Writing - Original Draft, Writing - Review \& Editing. AA: Methodology, Data Curation, Formal Analysis, Visualization, Writing - Original Draft, Writing - Review \& Editing. DW: Data Curation, Writing - Review \& Editing. ES: Methodology, Writing - Review \& Editing. SZ: Data Curation, Formal Analysis, Writing - Review \& Editing. RA: Conceptualization, Investigation, Methodology, Writing - Review \& Editing. KD: Methodology, Writing - Review \& Editing. SB: Methodology, Writing Review \& Editing. JS: Conceptualization, Methodology, Writing - Review \& Editing. KK: Conceptualization, Methodology, Supervision, Writing - Original Draft, Writing - Review \& Editing, Project administration, Funding acquisition. The author(s) read and approved the final manuscript.

\section{Funding}

This research was funded through the award of a Medical Research Council grant, 'Comparative evaluation of Spatio-Temporal Exposure Assessment Methods for estimating the health effects of air pollution (STEAM).' Grant code: MR/N014464/1.

\section{Availability of data and materials}

Under the terms of the data sharing agreement (see above), original patient level data is not available to external researchers.

\section{Declarations}

\section{Ethics approval and consent to participate}

All primary care data were extracted under the terms of a signed data sharing agreement with each practice and with project-specific approval following submission of a data privacy impact assessment, approved by the Caldicott Guardian, Lambeth Clinical Commissioning Group, on 12th March 2018. Separate ethical committee approval was not required (Health Research Authority, personal correspondence, 29 September 2017) since all data were fully anonymised for the purposes of research access, and all patient identifiable data had been removed.

Consent for publication

Not applicable.

\section{Competing interests}

The authors declare that they have no competing interests.

\section{Author details}

'School of Population Health and Environmental Sciences, King's College London, Guy's Campus, Addison House, London SE1 1UL, UK. ${ }^{2}$ Medical School, National and Kapodistrian University of Athens, Athens, Greece. ${ }^{3}$ Population Health Research Institute, St George's, University of London, Cranmer Terrace, London SW170RE, UK. Environmental Research Group, MRC Centre for Environment and Health, Imperial College, London, UK. ${ }^{5}$ Departments of Environmental Health and Epidemiology, Harvard TH Chan School of Public Health, 665 Huntington Avenue, Building 1, Room 1301, Boston, MA 02115, USA.

Received: 12 November 2020 Accepted: 14 April 2021

Published online: 07 May 2021

\section{References}

1. WHO 2013. Review of evidence on health aspects of air pollution REVIHAAP project: final technical report. https://www.euro.who.int/en/ health-topics/environment-and-health/air-quality/publications/2013/ review-of-evidence-on-health-aspects-of-air-pollution-revihaap-project-fina -technical-report

2. Thurston GD, Kipen H, Annesi-Maesano I, Balmes J, Brook RD, Cromar K, et al. A joint ERS/ATS policy statement: what constitutes an adverse health effect of air pollution? An analytical framework. Eur Respir J. 2017:49(1): 1600419. https://doi.org/10.1183/13993003.00419-2016.

3. WHO 2013. Health risks of air pollution in Europe - HRAPIE project. Recommendations for concentration-response functions for cost-benefit analysis of particulate matter, ozone and nitrogen dioxide. https://www. euro.who.int/en/health-topics/environment-and-health/air-quality/publica tions/2013/health-risks-of-air-pollution-in-europe-hrapie-project.recommendations-for-concentrationresponse-functions-for-costbenefit-ana lysis-of-particulate-matter,-ozone-and-nitrogen-dioxide.

4. Sofianopoulou E, Rushton SP, Diggle PJ, Pless-Mulloli T. Association between respiratory prescribing, air pollution and deprivation, in primary health care. J Public Health (Oxf). 2013;35(4):502-9. https://doi.org/10.1093/pubmed/fdt1 07 Erratum in: J Public Health (Oxf). 2014 Mar;36(1):180. PMID: 24293452.

5. Laurent O, Pedrono G, Filleul L, Segala C, Lefranc A, Schillinger C, et al. Influence of socioeconomic deprivation on the relation between air pollution and beta-agonist sales for asthma. Chest. 2009;135(3):717-23. https://doi.org/10.1378/chest.08-1604.

6. Casas L, Simons K, Nawrot TS, Brasseur O, Declerck P, Buyl R, et al. Respiratory medication sales and urban air pollution in Brussels (2005 to 2011). Environ Int. 2016:94:576-82. https://doi.org/10.1016/j.envint.201 6.06.019.

7. Hajat S, Anderson HR, Atkinson RW, Haines A. Effects of air pollution on general practitioner consultations for upper respiratory diseases in London. Occup Environ Med. 2002;59(5):294-9. https://doi.org/10.1136/oem.59.5.294.

8. Butland BK, Samoli E, Atkinson RW, Barratt B, Beevers SD, Kitwiroon N, et al. Comparing the performance of air pollution models for nitrogen dioxide and ozone in the context of a multilevel epidemiological analysis. Environ Epidemiol. 2020;4(3):e093. https://doi.org/10.1097/EE9.0000000000000093.

9. Samoli E, Butland BK, Rodopoulou S, Atkinson RW, Barratt B, Beevers SD, et al. The impact of measurement error in modeled ambient particles exposures on health effect estimates in multilevel analysis. Environ Epidemiol. 2020;4(3):e094. https://doi.org/10.1097/EE9.0000000000000094.

10. Danesh Yazdi M, Kuang Z, Dimakopoulou K, Barratt B, Suel E, Amini H, et al. Predicting Fine Particulate Matter (PM2.5) in the Greater London Area: An Ensemble Approach using Machine Learning Methods. Remote Sensing. 2020;12(6):914. https://doi.org/10.3390/rs12060914.

11. Lambeth DataNet, Lambeth CCG: https://www.lambethccg.nhs.uk/your-hea Ith/Information-for-patients/lambeth-datanet/Pages/default.aspx. Accessed 6 Apr 2021. 
12. Office of National Statistics, census geography, 2016. https://www.ons.gov. uk/methodology/geography/ukgeographies/censusgeography. Accessed 6 Apr 2021.

13. London Air Quality Network: http://www.londonair.org.uk/. Accessed 6 Apr 2021.

14. Air Quality England: http://www.airqualityengland.co.uk/. Accessed 6 Apr 2021.

15. Automatic Urban and Rural Network: http://www.nationalarchives.gov.uk/ doc/open-government-licence/version/2/. Accessed 6 Apr 2021.

16. Analitis A, Barratt B, Green D, Beddows A, Samoli E, Schwartz J, et al. Prediction of PM2.5 concentrations at the locations of monitoring sites measuring PM10 and NOx using generalized additive models and machine learning methods: a case study in London. Atmos Environ. 2020;240:117757. https://doi.org/10.1016/j.atmosenv.2020.117757.

17. Shi L, Zanobetti A, Kloog I, Coull BA, Koutrakis P, Melly SJ, et al. Lowconcentration PM2.5 and mortality: estimating acute and chronic effects in a population-based study. Environ Health Perspect. 2016;124(1):46-52. https://doi.org/10.1289/ehp.1409111.

18. Kloog I, Coull BA, Zanobetti A, Koutrakis P, Schwartz JD. Acute and chronic effects of particles on hospital admissions in new-England. Plos One. 2012; 7(4):e34664. https://doi.org/10.1371/journal.pone.0034664.

19. Zhang Y, Cui L, Xu D, He MZ, Zhou J, Han L, et al. The association of ambient PM2.5 with school absence and symptoms in schoolchildren: a panel study. Pediatr Res. 2018;84(1):28-33. https://doi.org/10.1038/s41390-01 8-0004-1.

20. English Indices of Deprivation, 2015. https://data.gov.uk/dataset/englishindices-of-deprivation-2015-Isoa-level. Accessed 6 Apr 2021

21. Katsouyanni K, Samet JM, Anderson HR, Atkinson R, Le Tertre A, Medina S, Samoli E, Touloumi G, Burnett RT, Krewski D, Ramsay T, Dominici F, Peng RD, Schwartz J, Zanobetti A; HEl Health Review Committee. Air pollution and health: a European and North American approach (APHENA). Res Rep Health Eff Inst. 2009 (142):5-90. https://pubmed.ncbi.nlm.nih.gov/20073322/. Accessed 6 Apr 2021.

22. Raaschou-Nielsen O, Andersen ZJ, Beelen R, Samoli E, Stafoggia M, Weinmayr G, et al. Air pollution and lung cancer incidence in 17 European cohorts: prospective analyses from the European Study of Cohorts for Air Pollution Effects (ESCAPE). Lancet Oncol. 2013;14(9):813-22. https://doi.org/1 0.1016/S1470-2045(13)70279-1.

23. Yitshak-Sade M, Bobb JF, Schwartz JD, Kloog I, Zanobetti A. The association between short and long-term exposure to PM2.5 and temperature and hospital admissions in New England and the synergistic effect of the shortterm exposures. Sci Total Environ. 2018;639:868-75. https://doi.org/10.1016/j. scitotenv.2018.05.181.

24. Groves CP, Butland BK, Atkinson RW, Delaney AP, Pilcher DV. Intensive care admissions and outcomes associated with short-term exposure to ambient air pollution: a time series analysis. Intensive Care Med. 2020;46(6):1213-21. https://doi.org/10.1007/s00134-020-06052-z.

25. Karakatsani A, Samoli E, Rodopoulou S, Dimakopoulou K, Papakosta D, Spyratos D, et al. Weekly personal ozone exposure and respiratory health in a panel of Greek schoolchildren. Environ Health Perspect. 2017;125(7): 077016. https://doi.org/10.1289/EHP635.

26. Zhang X, Pei YF, Zhang L, Guo B, Pendegraft AH, Zhuang W, et al. Negative binomial mixed models for analyzing longitudinal microbiome data. Front Microbiol. 2018;9:1683. https://doi.org/10.3389/fmicb.2018.01683.

27. Nhung NTT, Amini H, Schindler C, Kutlar Joss M, Dien TM, Probst-Hensch N, et al. Short-term association between ambient air pollution and pneumonia in children: a systematic review and meta-analysis of time-series and casecrossover studies. Environ Pollut. 2017;230:1000-8. https://doi.org/10.1016/j. envpol.2017.07.063.

28. Danesh-Yazdi M, Wang Y, Di Q, Zanobetti A, Schwartz J. Long-term exposure to PM2.5 and ozone and hospital admissions of Medicare participants in the Southeast USA. Environ Int. 2019;130:104879. https://doi. org/10.1016/j.envint.2019.05.073.

29. Brauer M, Freedman G, Frostad J, van Donkelaar A, Martin R, et al. Ambient air pollution exposure estimation for the global burden of disease 2013. Environ Sci Technol. 2016;50(1):79-88. https://pubs.acs.org/doi/abs/10.1 021/acs.est.5b03709

30. Crippa M, Guizzardi D, Muntean M, Schaaf E, Dentener F, van Aardenne J, Monni S, Doering U, Olivier J, Pagliari V, Janssens-Maenhout G. Gridded Emissions of Air Pollutants for the period 1970-2012 within EDGAR v4.3.2. Earth Syst. Sci. Data Discuss., 2018. doi: https://doi.org/10.5194/essd-2018-31.

\section{Publisher's Note}

Springer Nature remains neutral with regard to jurisdictional claims in published maps and institutional affiliations.
Ready to submit your research? Choose BMC and benefit from:

- fast, convenient online submission

- thorough peer review by experienced researchers in your field

- rapid publication on acceptance

- support for research data, including large and complex data types

- gold Open Access which fosters wider collaboration and increased citations

- maximum visibility for your research: over $100 \mathrm{M}$ website views per year

At BMC, research is always in progress.

Learn more biomedcentral.com/submissions 